\title{
Severe hemophilia B
}

INSERM

\section{Source}

INSERM. (1999). Orphanet: an online rare disease and orphan drug data base. Severe hemophilia B. ORPHA:169793

Severe hemophilia B is a form of hemophilia B (see this term) characterized by a large deficiency of factor IX leading to frequent spontaneous hemorrhage and abnormal bleeding as a result of minor injuries, or following surgery or tooth extraction. 